\title{
Osseous metaplasia in a tubular adenoma of the colon
}

\author{
W I Al-Daraji, A Abdellaoui, W D Salman
}

J Clin Pathol 2005;58:220-221. doi: 10.1136/jcp.2004.020685

An 85 year old woman presented with a one month history of change in her bowel habits in the form of alternating diarrhoea and constipation. She also noted some rectal bleeding. Flexible sigmoidoscopy revealed a $1.5 \mathrm{~cm}$ polyp $30 \mathrm{~cm}$ from the anus. The polyp was removed during the sigmoidoscopy by electrocautery and sent for histological examination. The polyp was a tubular adenoma with mild dysplasia. The adenoma contained numerous foci of metaplastic bone. These consisted of irregular islands of mineralised osteoid bone rimmed by a layer of scattered osteoblasts. This is the first case of osseous metaplasia in a tubular adenoma of the colon to be reported.

A n 85 year old woman presented with a one month history of change in her bowel habits in the form of alternating diarrhoea and constipation. She also noted some rectal bleeding. On physical examination she was fit and had no organomegaly or palpable lymph nodes. All haematological and biochemical investigations were within normal limits. Flexible sigmoidoscopy revealed a $1.5 \mathrm{~cm}$ polyp $30 \mathrm{~cm}$ from the anus. The polyp was removed during the sigmoidoscopy by electrocautery and sent for histological examination.

\section{HISTOPATHOLOGY}

Macroscopically, the specimen was a $15 \times 10 \times 8 \mathrm{~mm}$ pale brown polyp. For conventional light microscopy, the tissue was fixed in $10 \%$ formalin, embedded in paraffin wax, and $4 \mu \mathrm{m}$ thick sections were cut and stained with haematoxylin and eosin. The polyp was a tubular adenoma with mild dysplasia. The adenoma contained numerous foci of metaplastic bone (fig 1). These consisted of irregular islands of mineralised osteoid bone rimmed by a layer of scattered osteoblasts.

\section{DISCUSSION}

The formation of bone outside the skeletal system occurs in many pathological conditions, and may be clinically important, as in generalised myositis ossificans, or may represent an incidental finding. In both situations, the ossification process is initiated by a local osteogenic factor, which stimulates osteoblasts to differentiate and synthesise ground substance and collagen. Hydroxyapatite crystal formation, which is the final step in bone formation, depends on the presence of an adequate concentration of calcium and phosphate. ${ }^{1}$ Randall et al suggested that metastatic colonic carcinoma can promote heterotopic ossification, and that alkaline phosphatase is intimately associated with bone formation under these pathological conditions because immunostaining for alkaline phosphatase is not only seen in osteoblast-like cells, but also in apical membranes of the cancer cells next to areas of bone formation. ${ }^{2}$

Dukes in 1939 published the seminal paper describing osseous metaplasia in rectal cancer. ${ }^{3}$ Bone formation is a rare phenomenon in the gastrointestinal tract being associated with mucin producing tumours of the rectum, colon, and appendix. ${ }^{4}$ Osseous metaplasia in a benign colonic polyp has also been reported once by Sperling and Friedman. ${ }^{6}$ With the rectum being the most common site of osseous metaplasia (especially in malignant cases, with a prevalence of $0.4 \%),{ }^{7}$ it is notable that only two cases have been reported in the rectum describing osseous metaplasia in a tubular adenoma ${ }^{8}$ and a tubulovillous adenoma. ${ }^{9}$ To the best of our knowledge, this is the first reported case of osseous metaplasia in a tubular adenoma of the colon.

Although the exact mechanism of metaplasia in our case is not clear, we suggest that osseous metaplasia in a tubular adenoma, as in any adenocarcinomas of the gastrointestinal tract, results from direct contact with the adenoma cells or is the result of factors released from adenoma cells, which are
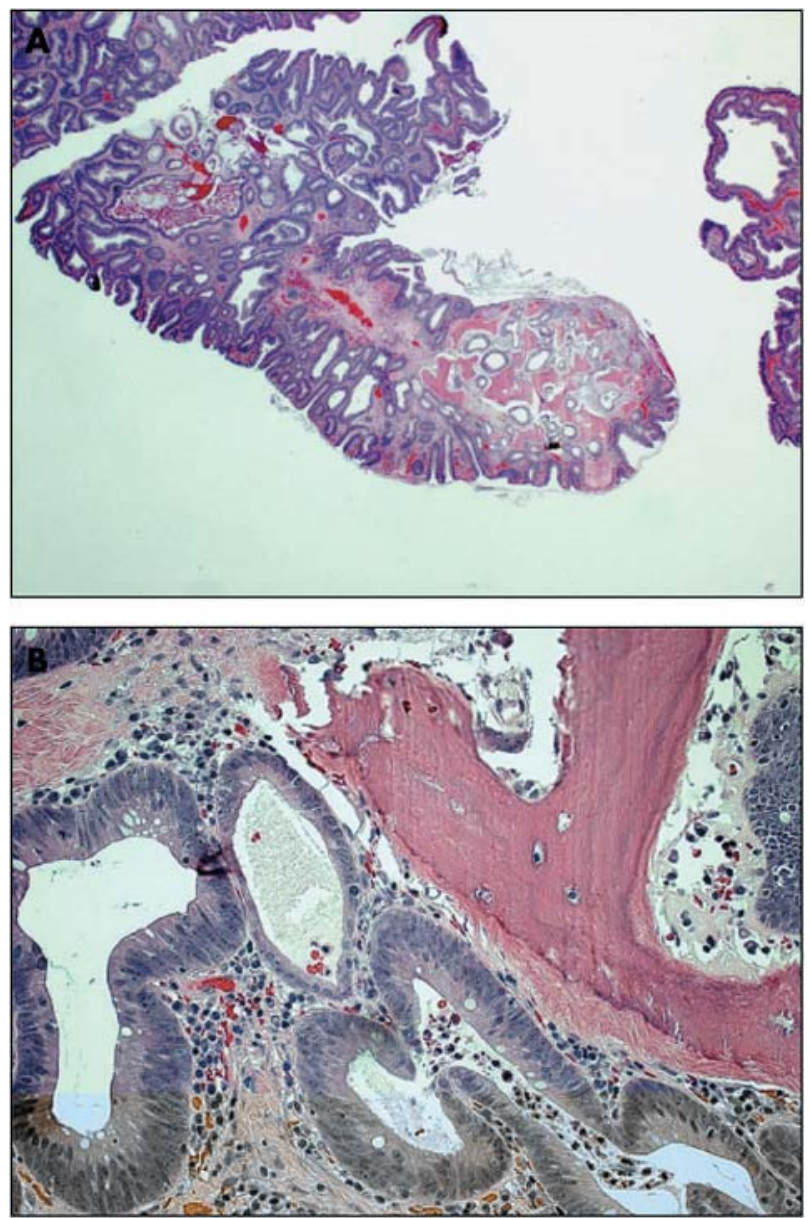

Figure 1 Histopathological appearance of osseous metaplasia in a colonic tubular adenoma. (A) Sections stained with haematoxylin and eosin showing a tubular adenoma with foci of metaplastic bone (original magnification, $\times 5$ ). (B) Haematoxylin and eosin stained sections showing dysplastic colon glands with focal stromal osseous metaplasia (original magnification, $\times 20$ ). 


\section{Take home messages}

- We report the first case of osseous metaplasia in a tubular adenoma of the colon

- Although the exact mechanism of osseous metaplasia in is not clear, we suggest that it results from direct contact with the adenoma cells or is the result of factors released from adenoma cells, which are yet to be identified

yet to be identified. Therefore, a "cause and effect" association needs to be investigated and established.

\section{Authors' affiliations}

W I Al-Daraii, W D Salman, Department of Histopathology, East Lancashire Hospitals, Burnley BB10 2PQ, UK

A Abdellaoui, Department of Surgery, East Lancashire Hospitals
Correspondence to: Dr W I Al-Daraii, Department of Histopathology, East Lancashire Hospitals, Burnley BB10 2PQ, UK; waldaraji@aol.com

Accepted for publication 24 August 2004

\section{REFERENCES}

1 Van Patter HT, Whittick JW. Heterotopic ossification in intestinal neoplasms. Am J Pathol 1955;31:73-91.

2 Randall JC, Morris DC, Tomita T, et al. Heterotopic ossification: a case report and immunohistochemical observations. Hum Pathol 1989;20:86-8

3 Dukes CE. Ossification in rectal cancer. Proc R Soc Med 1939;32:1489-94.

$4 \mathrm{Hall}$ CW. Calcification and osseous metaplasia in carcinoma of the colon. J Can Assoc Radiol 1962;13:135-9.

5 Alper M, Akyurek N, Patiroglu TE, et al. Heterotopic bone formation in two cases of colon carcinoma. Scand J Gastroenterol 2000;35:556-8.

6 Sperling MH, Friedman CJ. Osseous metaplasia in a benign colon polyp. Gastrointest Endosc 1981;27:198-9.

7 Govoni AF, Alcantara AN. Ossifying metastatic carcinoma of the colon. Am J Roentgenol Radium Ther Nud Med 1968;104:561-5.

8 Byard RW, Thomas MJ. Osseous metaplasia within tumours. A review of 11 cases. Ann Pathol 1988;8:64-6.

9 Groisman GM, Benkov KJ, Adsay V, et al. Osseous metaplasia in benign colorectal polyps. Arch Pathol Lab Med 1994;118:64-5. 